\title{
ECOLOGIA DA PAISAGEM DE REMANESCENTES FLORESTAIS NA BACIA HIDROGRÁFICA DO RIBEIRÃO DAS PEDRAS - CAMPINAS-SP ${ }^{1}$
}

\author{
Thiago Luiz Etto², Regina Márcia Longo ${ }^{3}$, Daniela da Rosa Arruda ${ }^{4}$ e Renata Invenioni ${ }^{4}$
}

\begin{abstract}
RESUMO - A fragmentação dos extratos florestais e o uso de terras, muitas vezes sem os cuidados necessários para mitigação dos impactos decorrentes das atividades antrópicas, geram ecossistemas fragilizados por fenômenos como o efeito de borda, ou seja, alterações localizadas nas áreas de contato entre a matriz antropizada e o remanescente florestal. Nesse contexto, este trabalho teve por objetivo estudar a fragilidade dos fragmentos encontrados na Bacia Hidrográfica do Ribeirão das Pedras, no Município de Campinas, SP, Brasil, utilizando técnicas de geoprocessamento. Com a base cartográfica do município, avaliaram-se o tamanho do fragmento e a tendência de formato alongado ou circular. Com base em dados cartográficos de 1962, 1972 e 2006, observou-se o declínio quantitativo e qualitativo dos fragmentos. Devido ao processo de urbanização não planejada do município, os fragmentos de menor área foram desmatados. Estes, apesar de não terem capacidade ecológica para sustentar níveis tróficos mais elevados, servem como "trampolins ecológicos”, contribuindo para o fluxo biológico. De maneira análoga, os remanescentes maiores também foram desmatados e sua área, reduzida. De maneira geral, o formato dos fragmentos passou a tender para o formato alongado, o que sugere maior contato entre os remanescentes e a matriz antrópica, aumentando, assim, a vulnerabilidade dos fragmentos. Destaca-se o caso do remanescente de Cerrado encontrado no extremo nordeste da bacia que possui tendência de formato alongado $(\mathrm{IC}=0,62)$ e área reduzida $(0,38$ ha), mostrando-se, assim, muito vulnerável às pressões antrópicas. Assim, conclui-se que os fragmentos florestais da bacia hidrográfica estudada estão altamente vulneráveis.
\end{abstract}

Palavras-chave: Ecologia de paisagem; Florestas urbanas; Fragilidade ambiental.

\section{LANDSCAPE ECOLOGY OF THE FOREST FRAGMENTS OF RIBEIRÃO DAS PEDRAS WATERSHED - CAMPINAS, SÃO PAULO STATE}

\begin{abstract}
Due to the fragmentation of forest extracts and land use, often without necessary care to mitigate the impacts resulting from activities performed on it, they are being weakened by a phenomenon such as the effect of edge, which consists of localized changes in the contact areas between the matrix and the disturbed forest fragment. The edge effects cause disruption, which is reflected in changes in the physical environment (abiotic). Those changes consist on the modification of microclimate in the edge zones, wind incidence, humidity and solar radiation, and the biota, and cause direct consequences on the variation of the distribution and individuals density of a specie. In this context, the present study aimed to assess the fragility of the fragments found in Ribeirao das Pedras watershed, Campinas, Brazil. We evaluated the fragment size and the tendency of elongated or circular using GIS techniques, and the existing cartographic base in town. According to the 1962, 1972 and 2006 cartographic database, was observed a decrease in quantity and quality of the fragments. Due to the unplanned urbanization of the municipality, the smaller fragments were deforested area. These, although not ecological capable to sustain higher trophic levels, serve as "stepping stones", contributing to the biological flow. Similarly, the largest fragments were also cleared and its area reduced.
\end{abstract}

\footnotetext{
${ }^{1}$ Recebido em 13.12.2011 aceito para publicação em 23.10.2013.

${ }^{2}$ Mestrado em Engenharia Civil, UNICAMP, Brasil. E-mail:<thiago_etto@yahoo.com.br>.

${ }^{3}$ Faculdade de Engenharia Ambiental, PUC-Campinas, Brasil. E-mail:<rmlongo@uol.com.br $>$.

${ }^{4}$ Graduada em Engenharia Ambiental,PUC-Campinas, Brasil. E-mail:<dani.arruda86@gmail.com>e < rinvenzioni@yahoo.com.br>.
} 
In general, the size of the fragments passed to tend to elongate shape, which suggests greater contact between the fragment and the anthropogenic matrix, thereby increasing the vulnerability of the fragments. We highlight the case of the Cerrado remnant found in the extreme northeast of the basin that has a tendency of elongated shape $(C I=0.62)$ and small area $(0.38 \mathrm{ha})$, thus proving to be very vulnerable to human pressures.

Keywords: Landscape ecology; Urban forest; Environmental fragility.

\section{INTRODUÇÃO}

Ecologia de paisagem é definida como o estudo das séries “métricas” ou "índices” de paisagem, visando à comparação de duas paisagens: os processos funcionais e os padrões de paisagem (VALENTE; VETTORAZZI, 2002). Para Naveh e Lieberman (1994), este é um conceito que permite uma abordagem ecossistêmica, aliando conhecimentos da geografia e da ecologia.

Metzger (2001) dissertou sobre duas abordagens distintas para o estudo da ecologia de paisagem: a primeira, tida como abordagem geográfica (Escola Europeia), a qual utiliza como fundamentos a geografia humana, a fitossociologia, a biogeografia e áreas do planejamento regional. Essa corrente se foca no planejamento do uso do solo, dadas as suas potencialidades econômicas. A segunda, a abordagem ecológica, foca seus esforços no entendimento da influência da paisagem sobre processos ecológicos, utilizando-se de análises geoestatísticas, modelagens, conhecimentos dos ecossistemas e análises espaciais para a análise das métricas e quantificação da paisagem. Essa linha de pensamento surgiu pela necessidade dos biogeógrafos e ecólogos americanos de adaptar a teoria de "biogeografia de ilhas", utilizada para o planejamento de reservas naturais em ambientes continentais.

Viana (1990) definiu fragmento florestal como qualquer área vegetada, interrompida por um elemento natural (lagos, rios etc.) ou antrópico (estradas, culturas agrícolas, entre outros), capaz de alterar a dinâmica do meio, a exemplo do fluxo de fauna, pólen ou sementes. Forman e Godron (1986) classificaram os elementos que compõem a paisagem em matrizes, manchas ou corredores.

As matrizes são as formações de áreas mais extensas e com menor isolamento. Esse elemento é considerado dominante, exercendo considerável controle sobre as dinâmicas de paisagem (FORMAN, 1995). McIntyre e Hobbs (1999) consideraram que as demais unidades de paisagem estão contidas na matriz, refletindo as condições do hábitat, podendo este ser classificado como intacto, alterado ou antropizado.

As manchas são formações de formato não linear que abrangem menor área, enquanto os fragmentos estreitos, ladeados por outras ocupações em ambos os lados, são entendidos como corredores. Estes têm função de controle do fluxo hídrico e biológico no meio (FORMAN; GODRON, 1986). Metzger (2003) dissertou sobre a formação das "ilhas de diversidade" ocasionadas pelas ações humanas que ocasionaram a fragmentação dos grandes aglomerados florestais.

Os remanescentes florestais estão vulneráveis a mudanças físicas e biogeográficas, em grande ou pequena escala, sendo o grau de vulnerabilidade função do tamanho, da forma, do posicionamento e da conectividade (BROWN JUNIOR; HUTCHINGS, 1997). Segundo Kapo (1989), a relação entre tamanho do hábitat e a sua vulnerabilidade é inversamente proporcional, sendo preponderante na dinâmica populacional e efeitos de borda.

Forman e Godron (1986) citaram a importância dos fragmentos de pequena área como trampolins ecológicos (stepping stones), ou seja, servem de ligação entre os fragmentos de grandes áreas, biodiversidade, entre outros, melhorando o nível de heterogeneidade da matriz e servindo como abrigo de espécies endêmicas. Assim, fragmentos com grandes extensões são vitais para manutenção da biodiversidade e de processos ecológicos de maiores proporções.

O efeito de borda é um fenômeno que pode reduzir ainda mais as áreas dos fragmentos. É um efeito deletério que adentra na área do fragmento por diversos metros e tem influência em diversos processos ecológicos (RIBEIRO; MARQUES, 2005).

As mudanças das áreas de borda provocam alterações no meio abiótico, como o microclima, incidência de ventos, umidade e radiação solar; e no meio biótico, que são decorrentes das transformações impostas ao meio físico, provocando variações diretas, que correspondem à mudança de distribuição e densidade

Revista Árvore, Viçosa-MG, v.37, n.6, p.1063-1071, 2013

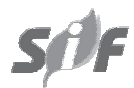


de indivíduos de uma mesma espécie. Lima-Ribeiro (2008) citou como exemplo o aumento da quantidade de exemplares de dada espécie em áreas de borda devido ao aumento da produção primária decorrente do aumento da incidência solar. As variações indiretas no meio biótico dizem respeito às interações entre as diversas espécies encontradas no remanescente, como a dispersão de sementes, polinização, predação e parasitismo.

A abrangência da borda é função do formato do fragmento, ou seja, quanto mais próximo da forma circular, menor a borda do fragmento, portanto menor será sua suscetibilidade às perturbações externas (ZUDEIMA, 1996).

A conectividade ou grau de isolamento é de imensa relevância na dinâmica da paisagem, sendo esta calculada por meio da menor distância borda-borda entre dois fragmentos, no que se refere a fragmento, classe e paisagem (HANSON et al., 1990; CASTRO, 2004; CALEGARI et al., 2010). Metzger (2003) definiu a conectividade da paisagem pela intensidade da movimentação inter-hábitat dos organismos, ou seja, a maior ou menor capacidade da paisagem em interferir nos fluxos biológicos (sementes, pólen ou organismos).

\section{MATERIAL E MÉTODOS}

A área de estudo encontra-se na Bacia Hidrográfica do Ribeirão das Pedras, Município de Campinas, SP, sendo delimitada pelas coordenadas $22^{\circ} 47^{\prime} 10^{\prime \prime}$ e $22^{\circ} 52^{\prime} 20^{\prime \prime}$ 'S e $47^{\circ} 07^{\prime} 15^{\prime \prime}$ e $46^{\circ}$ 02' $15^{\prime \prime}$ O (DAGNINO, 2007).

Este estudo se estende por uma área aproximada de 29,70 km², onde residem mais de 36 mil habitantes. A ocupação da área de drenagem é constituída por 52,6\% de construções, 33,7\% utilizada para fins agrícolas e 12,2\% de áreas vegetadas (DAGNINO, 2007).

De acordo com Torres et al. (2006), classificou-se a vegetação dos remanescentes florestais, como:

- Macegas: áreas ocupadas por pequenos arbustos e gramíneas.

- Mata: formações florestais como remanescentes florestais, reflorestamentos com essências nativas ou maciços arbóreos.

- Cerrado: extrato lenhoso, constituído por árvores e arbustos, ou um estrato herbáceo, formado por ervas e subarbustos.
- Capoeira: vegetação na qual predominam gramíneas, arbustos e pequenas árvores.

- Várzea: áreas cobertas por arbustos e taboas próximos a corpos d'água ou a montante de lagoas.

Por meio do banco de dados cartográficos de 1962, 1972 e 2006, gerados por Adami et al. (2006) e utilizando o software ArcGis 9.0, calcularam-se as áreas, os perímetros e o grau de isolamento, que consiste na menor distância euclidiana entre as bordas de dois fragmentos.

A forma do fragmento foi calculada através do índice de circularidade, ou seja, da proximidade do formato do remanescente com o formato de uma circunferência, em que a área de borda é minimizada em relação à área (CHATURVEDI et al., 1926 apud OLIVEIRA, et al., 2005; GREGGIO et al., 2009). O índice de circularidade é dado pela fórmula:

$$
I C=\frac{2 \cdot \sqrt{\pi \cdot S}}{P}
$$

em que IC = índice de circularidade; $\mathrm{S}$ = área do fragmento florestal; e P = perímetro do mesmo fragmento.

Os índices calculados foram, então, classificados segundo Nascimento et al. (2006), em que IC acima de 0,85 é considerado ótimo, pois possui forte semelhança com uma forma arredondada. Com valores desse índice variando de 0,65 a 0,85, entende-se que o fragmento tem tendência moderadamente alongada; e de 0,30 a 0,65, fragmentos alongados. Segundo Almeida (2008), fragmentos com área (S) inferior a 5 ha são considerados pequenos, de 5 a 50 ha médios e maiores que 50 ha grandes.

\section{RESULTADOS}

Na Figura 1 é possível observar as alterações na paisagem decorrentes do uso e ocupação do solo. De maneira geral, observou-se declínio na sucessão natural de algumas áreas. Por exemplo, o remanescente de mata na Fazenda Rio das Pedras, localizado na porção Noroeste da bacia, passou a ser ocupado por áreas rurais e macegas em 1972, e em 2006 foi ocupado por atividades tipicamente urbanas; tal ação oferece forte fator de pressão a um dos maiores fragmentos da bacia hidrográfica.

Intensa impermeabilização foi observada também nas partes Norte e Nordeste da bacia. De 1962 para 1972, áreas onde se localizavam pastos, pastos sujos, macegas e várzeas passaram a ser ocupadas por conglomerados urbanos. Em 2006, a situação agravou-se,

Revista Árvore, Viçosa-MG, v.37, n.6, p.1063-1071, 2013 
ETTO, T.L. et al.
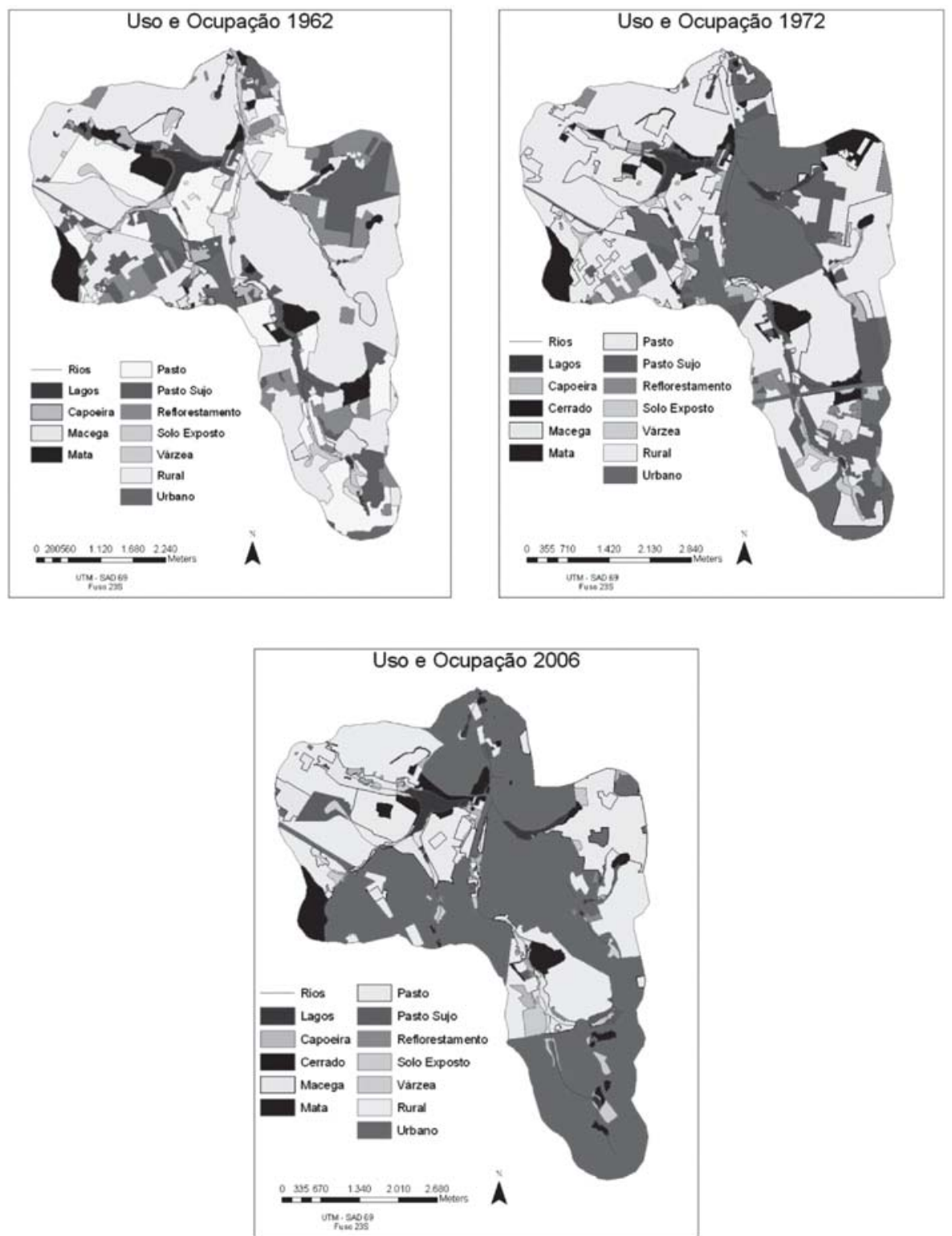

Figura 1 - Uso e ocupação do solo da Bacia Hidrográfica do Ribeirão das Pedras em 1962, 1972 e 2006. Figure 1 - Land use and occupation of Ribeirao das Pedras watershed in 1962, 1972 and 2006.

e ocorreu o mesmo na porção central da bacia hidrográfica, impactando, principalmente, a mata Santa Genebrinha, outro grande fragmento da bacia. A mesma área ainda foi ocupada por plantação de soja.

Na Região Sul, o crescimento urbano pressionou as áreas de vegetação mais desenvolvidas, o que resultou na formação de fragmentos de macega.
De 1962 a 1972, houve aumento equivalente a 16,24\% da área vegetada. Tal incremento se deveu, sobretudo, ao aumento da área ocupada por macegas, mostrando a recuperação de áreas degradadas.

Em 2006, observou-se uma área vegetada de 352,63 ha, quando em 1972 equivalia a 657,57 ha e, em 1962, a 550,79 ha, representando reduções de 86,48\% e 56,20\%, respectivamente, em relação a 2006.

Revista Árvore, Viçosa-MG, v.37, n.6, p.1063-1071, 2013 
Dos remanescentes florestais encontrados na bacia hidrográfica no ano 2006, a grande maioria encontrava-se no formato muito alongado ou alongado (Tabela 1 ). Dos sete remanescentes com área até 50 ha, cinco têm formato muito alongado e dois são alongados. Encontram-se três remanescentes considerados como unidades de conservação, a Mata Santa Genebra, a Mata Santa Genebrinha e a Mata da Fazendo do Rio das Pedras. Nessas matas são observados fortes traços de impactos nas áreas de borda.

Com relação aos remanescentes de mata, observou-se aumento no número dos fragmentos de $1962(\mathrm{n}=45)$ em relação a $1972(\mathrm{n}=49)$, assim como declínio da área vegetada (228,41 e 224,99 ha, respectivamente), mostrando a fragmentação do hábitat. A Figura 2 mostra o processo de fragmentação ocorrido na área de estudo.

Os remanescentes encontram-se, em grande parte, altamente vulneráveis (regiões 1A e 1B da Figura 3) às ações desenvolvidas na matriz antrópica (22 fragmentos, representando 34,4\%), pois possuem área reduzida (menor que 5 ha) e forma muito alongada $(\mathrm{IC}<0,65)$. Nesse grupo, encontra-se o único remanescente de Cerrado na bacia, o qual ocupa 0,38 ha $(\mathrm{IC}=0,62)$.
Outros 23 fragmentos (35,94\%) apresentam-se com formato alongado $(0,65<\mathrm{IC}<0,85)$ e área também reduzida (1C), e apenas três fragmentos muito pequenos se encontravam próximos ao formato ideal (1D).

Apenas 16 remanescentes (25\%) têm área superior a 5 ha, e 13 remanescentes apresentam-se fortemente alongados (2A e 2B) e três alongados (2C). Não há fragmentos grandes (com área superior a 50 ha) nessa bacia hidrográfica.

Considerando uma taxa de desmatamento linear durante os períodos não analisados, observa-se, de maneira geral, decréscimo acentuado de 1972 a 2006 (Figura 4). Pôde-se notar que, em geral, ocorreram incremento da área média dos fragmentos pequenos e declínio dos fragmentos de área média, com exceção dos fragmentos grandes de macega.

\section{DISCUSSÕES}

Segundo Zudeima (1996), os fragmentos alongados têm maior contato com a matriz antrópica. Tal fato acarreta problemas tanto para o fragmento, devido à sua maior área de borda e às suas consequências, quanto para a população que reside no seu entorno, dada a maior

Tabela 1 - Índice de circularidade e área (S) dos fragmentos florestais da Bacia Hidrográfica do Ribeirão das Pedras, em que $\mathrm{n}=$ número de ocorrências.

Table 1 - Circularity index and area (S) of forest fragments in the Ribeirao das Pedras watershed, where $n=$ number of occurrences.

\begin{tabular}{|c|c|c|c|c|c|c|c|c|c|c|c|c|c|c|c|}
\hline & & & & ce de & irculari & ade & & & & & & & rea & & \\
\hline & DTAL & & 0,3 & 0,3 & 0,65 & 0,6 & $-0,85$ & & 1,00 & & & $>5$ & & $5<S<50$ & \\
\hline & & $\mathrm{n}$ & (\%) & $\mathrm{n}$ & (\%) & $\mathrm{n}$ & (\%) & $\mathrm{n}$ & (\%) & $\mathrm{n}$ & total & média & $\mathrm{n}$ & ha & média \\
\hline 1962 Capoeira & 42 & 1 & 2,4 & 20 & 47,6 & 15 & 35,7 & 6 & 14,3 & 38 & 47,6 & 1,3 & 4 & 32,9 & 8,2 \\
\hline Cerrado & 0 & 0 & - & 0 & - & & 0 & - & 0 & - & 0 & 0,0 & 0,0 & 0 & 0,0 \\
\hline Macega & 31 & 2 & 6,5 & 21 & 67,7 & 7 & 22,6 & 1 & 3,2 & 19 & 37,1 & 2,0 & 12 & 112,9 & 9,4 \\
\hline Mata & 45 & 1 & 2,2 & 8 & 17,8 & 27 & 60,0 & 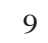 & 20,0 & 34 & 51,5 & 1,5 & 11 & 176,9 & 16,1 \\
\hline Várzea & 21 & 1 & 4,8 & 12 & 57,1 & 6 & 28,6 & 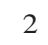 & 9 & 15 & 30,0 & 2,0 & 6 & 61,8 & 10,3 \\
\hline 1972 Capoeira & 30 & 2 & 6,7 & 11 & 36,7 & 11 & 36,7 & 6 & 20,0 & 25 & 40,9 & 1,6 & 5 & 37,4 & 7,5 \\
\hline Cerrado & 1 & 0 & 0,0 & 1 & 100,0 & 0 & 0,0 & 0 & 0,0 & 1 & 0,1 & 0,1 & 0 & 0,0 & 0,0 \\
\hline Macega & 44 & 1 & 2,3 & 28 & 63,6 & 14 & 31,8 & 1 & 2,3 & 27 & 39,8 & 1,5 & 17 & 250,0 & 14,7 \\
\hline Mata & 49 & 1 & 2,0 & 19 & 38,8 & 21 & 42,9 & 8 & 16,3 & 41 & 72,4 & 1,8 & 8 & 152,6 & 19,1 \\
\hline Várzea & 11 & 0 & 0,0 & 5 & 45,5 & 5 & 45,5 & 1 & 9,1 & 6 & 14,0 & 2,3 & 5 & 50,4 & 10,1 \\
\hline 2006 Capoeira & 15 & 0 & 0,0 & 8 & 53,3 & 6 & 40,0 & 1 & 6,7 & 13 & 19,1 & 1,7 & 2 & 12,9 & 6,4 \\
\hline Cerrado & 1 & 0 & 0,0 & 1 & 100,0 & 0 & 0,0 & 0 & 0,0 & 1 & 0,4 & 0,4 & 0 & 0,0 & 0,0 \\
\hline Macega & 12 & 1 & 8,3 & 8 & 66,7 & 3 & 25,0 & 0 & 0,0 & 8 & 27,8 & 3,5 & 5 & 122,9 & 24,6 \\
\hline Mata & 26 & 1 & 3,9 & 8 & 30,8 & 15 & 57,7 & 2 & 7,7 & 19 & 36,2 & 1,9 & 7 & 106,9 & 15,3 \\
\hline Várzea & 9 & 0 & 0,0 & 4 & 44,4 & 5 & 55,6 & 0 & 0,0 & 7 & 15,7 & 2,2 & 2 & 10,8 & 5,4 \\
\hline
\end{tabular}


probabilidade de contato com a fauna nativa, podendo, assim, ocasionar acidentes com animais peçonhentos e insetos.

Observou-se, na área de estudo, diminuição dos remanescentes médios, o que aponta para a possibilidade da fragmentação desses fragmentos de maior área em remanescentes menores e descontínuos. Destaca-se ainda o caso do remanescente de Cerrado encontrado

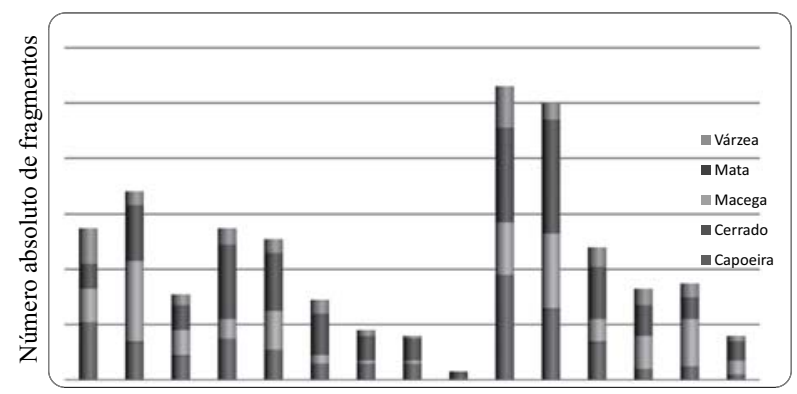

Figura 2 - Número absoluto (n) de fragmentos florestais e sua caracterização na Bacia Hidrográfica do Ribeirão das Pedras, em 1962, 1972 e 2006.

Figure 2 - Absolute number of forest fragments and its caracteristics in Ribeirao das Pedras Watershed in 1962, 1972 and 2006.

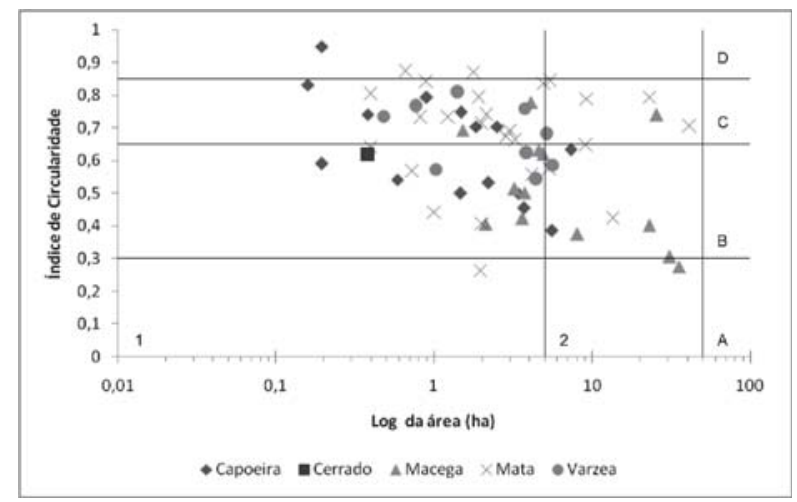

Figura 3 - Avaliação da fragilidade ambiental dos fragmentos florestais localizados na Bacia Hidrográfica do Ribeirão das Pedras em 2006 ( 1 = fragmentos pequenos; 2 = fragmentos médios; $\mathrm{A}$ = formato extremamente alongado; $\mathrm{B}=$ formato muito alongado; $\mathrm{C}$ = formato alongado; e $\mathrm{D}$ = formato circular).

Figure 3 -Evaluation of the environmental fragility of forest fragments in Ribeirao das Pedras watershed in 2006 ( 1 = small fragments; 2 = medium fragments; $A$ $=$ extremely elongated shape $B=$ very elongated shape; elongated shape; and $\mathrm{D}=$ circular shape). no extremo Nordeste da bacia. Este, além de ter formato alongado (IC = 0,62), ocupa uma área reduzida (0,38 ha). Assim, infere-se a extrema vulnerabilidade do bioma às ações antrópicas que o cercam.

Bierregaard Júnior et al. (1992) observaram aumento de ervas nas áreas de borda causada, provavelmente, pela ação dos herbicidas utilizados na cultura de soja no entorno de remanescentes florestais do Amazonas. Bierregaard Júnior et al. (2001) atribuíram as alterações biológicas nas áreas de borda provocadas por variações no meio físico à incidência de radiação e ventos, que por consequência modifica o microclima em fragmentos de Floresta Amazônica.

Fernandez (2005) também atribuiu muitos impactos à dinâmica da matriz devido ao contato com as ações antrópicas em seus estudos. Esse autor apontou que a fragmentação do hábitat impacta não somente os ambientes fragmentados, mas também os remanescentes contínuos, pois os fluxos biológicos são alterados como um todo. É conhecido que algumas espécies de fauna não transpõem faixas estreitas de ambientes abertos (SEAGLE, 1986).

O aumento da área de borda aumenta o risco de extinções de espécies (DALE et al., 1994). Espécies que requerem grande raio de ação ou têm hábitos territoriais são imediatamente impactadas por não encontrarem espaço hábil para sua sobrevivência

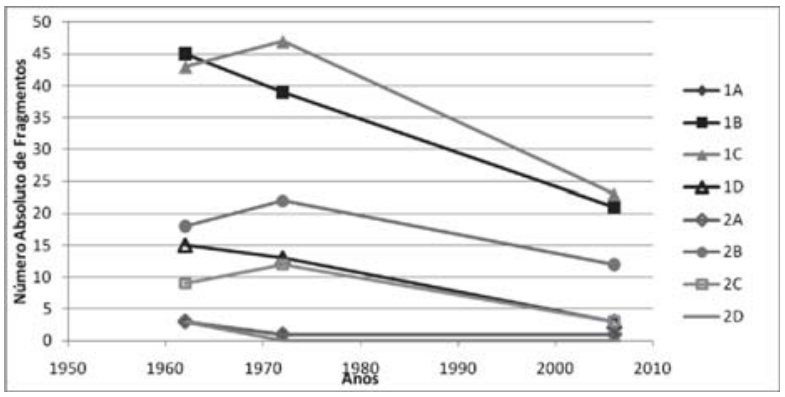

Figura 4 - Taxa de desmatamento de 1962 a 2006 da Bacia Hidrográfica do Ribeirão das Pedras ( 1 = fragmentos pequenos; 2 = fragmentos médios; $\mathrm{A}$ = formato extremamente alongado; $\mathrm{B}=$ formato muito alongado; $\mathrm{C}$ = formato alongado; e $\mathrm{D}$ = formato circular).

Figure 4-Deforestation rate from 1962 to 2006 in the Ribeirao das Pedras watershed $(1=$ small fragments; $2=$ medium fragments; $A$ = extremely elongated shape; $B=$ very elongated shape; elongated shape; and $D=$ circular shape).

Revista Árvore, Viçosa-MG, v.37, n.6, p.1063-1071, 2013 
(BIERREGAARD JÚNIOR et al., 1992), dado o aumento da competição intra e interespecífica (SEAGLE, 1986).

Em curto prazo, aumenta-se o risco da deriva genética, dada a redução das populações, inclusive com possibilidade de perder alelos. No longo prazo, o risco de endogamia, ocasionada pela maior probabilidade de autofecundação e acasalamento entre indivíduos aparentados, é potencializado (KAGEYAMA et al., 1998).

A fragmentação da matriz e, consequentemente, a perda de hábitat (FAHRIG, 2003) formam as "ilhas de diversidade” (DEBINSK; HOLT, 2000). Para Laurance e Bierregard Júnior (1997), o processo de fragmentação e a perda de hábitat estão intimamente relacionados.

Como previsto pelos estudos de Brown Junior e Hutchings (1997) e Tabarelli et al. (2004), fragmentos pequenos de formato circular, locados em meio a uma matriz com alto poder impactante, levarão à extinção de determinadas espécies e ao aumento das espécies pioneiras.

\section{CONCLUSÃO}

Os fragmentos florestais da Bacia Hidrográfica do Ribeirão das Pedras são altamente vulneráveis ao efeito de borda, pois são predominantemente constituídos de remanescentes com formato muito alongado e área de cobertura muito pequena.

Analisando os fragmentos ao longo do tempo, notou-se que estes tiveram diminuição quantitativa e também qualitativa, tanto no que diz respeito ao tamanho quanto ao formato dos fragmentos. A Bacia Hidrográfica do Ribeirão das Pedras passou de uma região com características rurais e grandes fragmentos florestais com extratos bem desenvolvidos para uso predominantemente urbano, o que ocasionou declínio e extinção de muitos remanescentes.

Portanto, os remanescentes florestais da Bacia Hidrográfica do Ribeirão das Pedras podem ser considerados altamente frágeis, e desde 1962 não existe fragmento hábil para a manutenção da biodiversidade genética e animais de porte maior, e os remanescentes de menor extensão, que servem como "trampolins ecológicos” para o fluxo biológico na área, também se encontram intensamente impactados pelas ações antrópicas.

\section{REFERÊNCIAS}

ADAMI, S. F. et al. Cartografia, sensoriamento remoto e sistemas de informações geográficas. In: TORRES, R. B. et al. (Coord.). Recuperação ambiental, participação e poder público: uma experiência em Campinas. Relatório de pesquisa. (Processo FAPESP n ${ }^{\circ}$. 01/02952-1), 2006.

\section{ALMEIDA, C. G. Análise especial dos fragmentos florestais na área do parque Nacional dos Campos Gerais, Paraná. 2008. 72f. Dissertação (Mestrado em Gestão do Território) Universidade Estadual de Ponta Grossa, Ponta Grossa, 2008.}

BIERREGAARD JÚNIOR, R. O. et al. The biological dynamics of tropical rain forest fragments. Bioscience, v.42, n.1, p.859-866, 1992.

BIERREGAARD JÚNIOR, R. O. et al. Lessons from Amazonia: the ecology and conservation of a fragmented forest. New Haven: Yale University Press, 2001.

BROWN JUNIOR., K. S.; HUTCHINGS, R. W. Disturbance, fragmentation, and the dynamics ofdiversity in Amazonian forest butterflies. In: LAURANCE, W. F.; BIERREGAARD JÚNIOR, R. O. (Ed.). Tropical forest remnants: ecology, management, and conservation of fragmented communities. Chicago: University of Chicago Press, 1997. p.91-110.

CALEGARI, L.et al. Análise da dinâmica de fragmentos florestais no município de Carandaí, MG, para fins de restauração florestal. Revista Árvore, v.34, n5, p.871-880, 2010.

CAStro, G. C. Análise da estrutura, diversidade florística e variações espaciais do componente arbóreo de corredores de vegetação na região do Alto Rio Grande, MG. 2004. 83f. Dissertação (Mestrado em Engenharia Florestal) Universidade Federal de Lavras, Lavras, 2004.

CHATURVEDI, M. D. Measurements of Forest Crops. Londres: Oxford University Press, 1926. 142p. 
DAGNINO, R. S. Riscos ambientais na bacia do Ribeirão das Pedras, Campinas - São Paulo. 2007. 126f. Dissertação (Mestrado em Geografia) Universidade Estadual de Campinas, Campinas, 2007.

DALE, V. H. et al. Relating patterns of land use change to faunal biodiversity in Central Amazon. Conservation Biology, v.8, n.4, p.1027-1036, 1994.

DEBINSKI, D.; HOLT, R. A survey and overview of habitats fragmentation. Conservation Biology, v.14, n.2, p.342-355, 2000.

FAHRIG, L. Effects of habitat fragmentation on biodiversity. Annual Review of Ecology, Evolution and Systematic, n.34, p-487-515, 2003.

FERNANDEZ, F. Aprendendo a lição de Chaco Canyon: do "desenvolvimento sustentável” a uma vida sustentável. Instituto Ethos Reflexão, v.15, p.3-19, 2005.

FORMAN, M.; GODRON, M. Landscape ecology. New York: Wiley, 1986. 619p.

FORMAN, R.T.T. Land mosaics: the ecology of landscapes and regions. Cambridge: Cambridge University Press, 1995. 632p.

GREGGIO, T. C.; PISSARA, C. T. P.; RODRIGUES, F. M. Avaliação dos fragmentos florestais no município de Jaboticabal-SP. Revista Árvore, v.33, n.1, p.117-124, 2009.

HANSON, J. S.; MALASON, G. P.; ARMSTRONG, M. P. Landscape fragmentation and dispersal in a model of riparian forest dynamics, Modeling, v.49, n.4, p.227-296, 1990.

KAGEYAMA, P. Y.; GANDARA, F. B.; INGLEZ DE SOUZA, L. M. Conseqüências genéticas da fragmentação sobre as populações de espécies arbóreas. IPEF, v.12, n.32, p.65-70, 1998.

KAPO, V. Effects of isolation on the water status of forest patches in the Brasilian Amazon. Journal of Tropical Ecology, v.2, n.5, p.173-185, 1989.

LAURANCE, W. F.; BIRREGAARD JÚNIOR, R. O. Tropical forest remnants: ecology, management, and conservation of fragmented communities. Chicago: University of Chicago Press, 1997. p.33-44.
LIMA-RIBEIRO, M. S. Efeito de borda sobre a vegetação e estruturação populacional em fragmentos de Cerradão no Sudoeste Goiano, Brasil. Acta Botanica Brasilica, v.22, p.535545, 2008.

MC INTYRE, S.; HOBBS, R. A. Framework for conceptualizing human effects on landscapes and its relevance to management and research models. Conservation Biology, v.13, n.6, p.1282-1292, 1999.

METZGER, J. P. O que é ecologia de paisagem?. Biota Neotropica, v.1, n.1, p.1-9, 2001.

METZGER, J. P. Delineamento de experimentos numa perspectiva de ecologia da paisagem. In: CULLEN JR., L; RUDRAN, R.; VALLADARESPADUA, C. (Ed.). Métodos de estudos em biologia da conservação e manejo da vida silvestre. Curitiba: UFPR/Fundação O Boticário de Proteção à Natureza, 2003. p.539-553.

NASCIMENTO, M. C. et al. Mapeamento dos fragmentos de vegetação florestal nativa da bacia hidrográfica do Rio Alegre, Espírito Santo, a partir de imagens do satélite IKONOS II, Revista Árvore, v.30, n.3, p.389-398, 2006.

NAVEH, Z.; LIEBERMAN, A. S. Landscape ecology: theory and application. New York: Springer-Verlag, 1994.

OLIVEIRA, M. L. R. et al. Equações de volume de povoamento para fragmentos florestais naturais do município de Viçosa-MG. Revista Árvore, v.29, n.2, p.213-225, 2005.

RIBEIRO, S.; MARQUES, J. C. B. Características da paisagem e sua relação concorrência de bugios-ruivos (Alouatta guariba clamitans Cabrera, 1940; Primates Atelidae) em fragmentos florestais no vale do Taquari, RS. Natureza e Conservação, v.3, n.2, p.65-78, 2005.

SEAGLE, S. W. Generation of species-area curves by a model of animal-habitat dynamics. In: VERNER, M. L.; MORRISSON, M. L.; RALPH, C. J. (Ed.). Wildlife 2000. Modeling habitat relationships of terrestrial vertebrates. Wisconsin: The University of Wisconsin Press, 1986. p.281-285. 
TABARELLI, M.; SILVA, J. M. C.; GASCON, C. Forest fragmentation, synergisms and the impoverishment of neotropical forests.

Biodiversity and Conservation, v.13, n.7, p.1419-1425, 2004.

TORRES, R. B. et al. A vegetação nativa remanescente na bacia do ribeirão das Anhumas. In: TORRES, R. B. et al. (Coord.).

Recuperação ambiental, participação e poder público: uma experiência em Campinas. Relatório de pesquisa. (Processo FAPESP nº. 01/02952-1), 2006.
VALENTE, R. O. A.; VETTORAZZI, C. A. Análise da estrutura da paisagem na Bacia do Rio Corumbatai, SP. Scientia Forestalis, v.62, p.114-129, 2002.

VIANA, V. M. Biologia e manejo de fragmentos florestais atuais. In: CONGRESSO BRASILEIRO FLORESTAL, 6., 1990, Campos do Jordão. Anais... Campos do Jordão: SBS/SBEF, 1990. p.113-118.

ZUDEIMA, P. A.; SAYER, J. A.; DIJKMAN, W. Forest fragmentation and biodiversity: the case for intermediate-sized conservation areas. Environmental Conservation, v.23, n.3, p.290-297, 1996. 
